\title{
QOGISAKI (QUARTED GIZI SEIMBANG MASA KINI) : PERMAINAN EDUKATIF, KOMUNIKATIF DAN INTERAKTIF BERBASIS NUTRITION EDUCATION
}

\section{QOGISAKI (QUARTED NUTRITION BALANCE NOW): EDUCATIONAL, COMMUNICATIVE AND INTERACTIVE GAME BASED ON NUTRITION EDUCATION}

\author{
Anesia Anggun Kinanti ${ }^{1}$, Siti Hadrianti ${ }^{2}$, Askar Yusuf ${ }^{3}$, Amina $^{4}$ Hapsah $^{5}$ \\ Keperawatan, Fakultas Kedokteran, Universitas Hasanuddin ${ }^{1,2,4,5}$ \\ Ilmu Gizi, Fakultas Kesehatan Masyarakat, Universitas Hasanuddin ${ }^{3}$
}

\begin{abstract}
ABSTRAK
Secara nasional, ketidakseimbangan nutrisi usia 5-12 tahun (menurut IMT/U) cukup tinggi. Prevalensi kegemukan mencapai 10,7\% (laki-laki) \& 7,7\% (perempuan); 11,2\% kurus, 3,9\% berat badan lebih (Riset Kesehatan Dasar, 2013). SD Inpres Kera-Kera Makassar memiliki angka underweight $( \pm 60$ orang) dan obesitas ( \pm 10 orang). Kemungkinan penyebab : pola makan kurang sehat akibat tingkat pengetahuan dan kecenderungan mengikuti trend makanan modern yang tinggi gula, garam, rendah serat dan berlemak tinggi (makanan cepat saji). Permainan Qogisaki (Quarted gizi seimbang masa kini) adalah modifikasi quarted yang edukatif, komunikatif dan interaktif berbasis nutrition education dilakukan pada anak kelas III, IV dan V (74 orang) di SD Inpres Kera-kera Makassar. Kegiatan berupa pretest, penyuluhan gizi seimbang, bermain quarted (FGD), posttest dan evaluasi isi quarted serta puzzle piring makanku. Perubahan ditunjukkan setelah 1 bulan dimana jumlah anak yang sering makan sayuran tiap hari meningkat dari 37 menjadi 52 anak, konsumsi air putih dari 34 menjadi 63 anak, konsumsi minuman manis menurun dari 39 menjadi 10 anak, menyukai makanan kurang sehat menjadi lebih menyukai makanan sehat meningkat (menyukai mie instan menurun dari $11 \mathrm{ke} 6$ anak, menyukai buah-buahan meningkat dari 29 menjadi 34 anak, tidak suka makan sayur menurun dari 2 menjadi 0 anak). Pengetahuan juga meningkat dari 69,1 menjadi 73,33 poin. Hasil evaluasi isi quarted : $52,4 \%$ menjawab semua (5) pertanyaan dengan benar dengan median skornya adalah 80 . Selain itu, $73 \%$ responden mampu menyusun menu sehari (menerapkan pedoman gizi seimbang). Qogisaki meningkatkan pengetahuan \& memperbaiki perilaku anak dalam pemenuhan nutrisi. Sehingga dapat digunakan sebagai upaya perbaikan gizi anak.
\end{abstract}

Kata Kunci: QOGISAKI, Gizi Lebih, Gizi Kurang

\begin{abstract}
Nationally, nutritional imbalance between 5-12 years old (according to BMI / U) is quite high. The prevalence of obesity reaches $10.7 \%$ (men) \& 7.7\% (women); $11.2 \%$ thin, $3.9 \%$ overweight (Basic Health Research, 2013). Makassar Monkey Inpres Elementary School has underweight numbers ( \pm 60 people) and obesity ( \pm 10 people). Possible causes: unhealthy eating patterns due to the level of knowledge and the tendency to follow modern food trends that are high in sugar, salt, low in fiber and high in fat (fast food). The game Qogisaki (Quarted balanced nutrition today) is an educational, communicative and interactive quarted modification based on nutrition education conducted for third, fourth and fifth graders (74 people) in Makassar Monkey Inpres Elementary School. The activities are in the form of pretest, balanced nutrition counseling, play quarted (FGD), posttest and evaluation of quarted contents and my dinner plate puzzle. Changes were shown after 1 month where the number of children who often ate vegetables every day increased from 37 to 52 children, consumption of water from 34 to 63 children, consumption of sweet drinks decreased from 39 to 10 children, liking unhealthy foods to becoming more like healthy food increased (liked instant noodles decreased from 11 to 6
\end{abstract}


children, liked fruits increased from 29 to 34 children, dislikes eating vegetables decreased from 2 to 0 children). Knowledge also increased from 69.1 to 73.33 points. Results of the quarted content evaluation: $52.4 \%$ answered all (5) questions correctly with a median score of 80 . In addition, $73 \%$ of respondents were able to compile a daily menu (implementing balanced nutrition guidelines). Qogisaki improves knowledge \& improves children's behavior in fulfilling nutrition. So that it can be used as an effort to improve children's nutrition.

Keywords: QOGISAKI, Overweight, Underweight

\section{Pendahuluan}

Beban gizi ganda (BGG) atau Double Burden of Malnutrition (DBM) adalah suatu keadaan koeksistensi antara kekurangan gizi dan kelebihan gizi makronutrien maupun mikronutrien disepanjang kehidupan pada populasi, masyarakat, keluarga dan bahkan individu yang sama. Food and Agriculture Organization (FAO) mengungkapkan secara umum kejadian gizi lebih mempunyai persentase yang lebih tinggi dibandingkan dengan gizi kurang, namun di negara berkembang persentase kurang gizi dan kelebihan gizi berimbang.Seperti beberapa negara berkembang lainnya, Indonesia sejak beberapa dekade terakhir ini tidak luput dari permasalahan tersebut, terutama pada anakbalita (Djaiman, 2015).

Menurut WHO, saat ini terdapat bukti bahwa prevalensi kelebihan berat badan (overweight) dan obesitas meningkat sangat tajam di seluruh dunia. Kejadian obesitas di negara-negara maju seperti di negara-negara Eropa, USA, dan Australia telah mencapai tingkatan epidemi. Akan tetapi hal ini tidak hanya terjadi di negara-negara maju, di beberapa negara-negara berkembang obesitas justru telah menjadi masalah kesehatan yang lebih serius (Hadi, 2005).

Masalah gizi masih menjadi masalah kesehatan masyarakat yang utama di negara berkembang termasuk Indonesia. Secara nasional masalah kegemukan pada anak umur 6-12 tahun masih tinggi yaitu $9,2 \%$ atau masih di atas 5,0\%, untuk jenis kelamin laki-laki 10,7\% dan perempuan 7,7\%. Prevalensi berat badan lebih pada kelompok umur yag sama untuk Sulawesi Selatan, yaitu 3,9\%. Berdasarkan Riset Kesehatan Dasar ( RISKESDAS) 2013 menunjukkan bahwa secara nasional prevalensi kurus (menurut IMT/U) pada anak umur 5-12 tahun adalah 11.2 persen, terdiri dari 4,0 persen sangat kurus dan 7,2 persen kurus.

Di Indonesia, pengurangan yang signifikan dalam kematian anak dan morbiditas dapat dikaitkan sebagian keberhasilan program suplementasi mikronutrien. Tidak seperti suplemen dan fortifikasi skema, makanan berdasarkan inisiatif telah menerima relatif sedikit perhatian dalam kebijakan nasional. Mengatasi penyebab dari kekurangan gizi: diet yang buruk kurang kalori dan mikronutrien, serta infeksi adalah kunci untuk mengatasi hal itu dengan cara yang berkelanjutan. (Ickowitz, Rowland, Powell, Salim, \& Sunderland, 2016).

Salah satu faktor yang berpengaruh besar ke perbaikan status gizi anak adalah intervensi pemberian edukasi. Karena edukasi masyarakat umumnya rendah, sehingga berdampak pada pengetahuan ibu yang sangat terbatas mengenai pola hidup sehat dan pentingnya zat gizi bagi kesehatan dan status gizi anak (devi, 2010).

Asupan gizi yang memadai pada anak usia dini adalah sangat penting untuk pertumbuhan optimal dan kesehatan di masa depan. Masalah kesehatan gizi anak adalah masalah kesehatan masyarakat yang utama. Tiga faktor yang mempengaruhi masalah kesehatan gizi anak secara langsung, yaitu anak tidak cukup mendapatkan makanan bergizi seimbang, anak tidak mendapat asupan gizi yang memadai dan anak mungkin menderita penyakit infeksi (Hilger, et al., 2015).

Terdapat banyak jenis game edukasi atau metode edukasi yang selama ini diterapkan sebagai media edukasi kesehatan, namun belum ada yang menerapkan metode permainan kuarted. Game Quarted adalah suatu cara yang membuat pengetahuan tentang gizi pada anak-anak meningkat sehingga anak- 
anak tidak mengalami kelebihan maupun kekurangan gizi. Game ini dimodifikasit agar anak-anak lebih memahami dan mengerti tentang gizi seimbang dengan membuat suatu permainan gambar yang menarik. Gambaran umum statug gizi pada subjek penelitian ini rata-rata mengalami gizi kurang oleh karena itu peniliti hadir dengan solusi permaian QOGISAKI yang edukatif, komunikatif dan interaktif.

Game Quarted yang akan penulis kembangkan adalah Quarted dengan penekanan pada pola hidup sehat terkhusus pada gizi seimbang, sehingga anak-anak akan terhindar dari kekurangan dan kelebihan gizi. Quarted ini akan memuat berbagai gambar-gambar yang mengandung berbagai pola hidup sehat dan makanan-makanan yang dapat menjaga tubuh agar tetap sehat. Penulis akan menuangkan program sehat kekinian sebagai media pembelajaran dan cara menerapkan gizi seimbang masa kini. Hal tersebut merupakan latar belakang penulis untuk menciptakan QOGISAKI (Quarted Gizi Seimbang Masa Kini) : Permainan Edukatif, Komunikatif Dan Interaktif Berbasis Nutrition Education dengan metode Focus Playing Group (FPG) dan pelatihan kreativitas. QOGISAKI ini dimaksudkan sebagai upaya peningkatan pengetahuan mengenai gizi seimbang di usia dini sebagai peningkatan kualitas hidup generasi yang akan datang.

\section{Subjek dan metode}

Jenis penelitian adalah penelitian Quasi Eksperiment Design, dengan melakukan pretest dan post-test. Lokasi penelitian ini adalah di Sekolah Dasar Inpres Kera-kera, Kecamatan Tamalanrea, Kabupaten Makassar yang dilaksanakan pada bulan April 2017. Populasi penelitian ini adalah siswa kelas II, IV DAN Vdi Sekolah Dasar Inpres Kera-kera, Kecamatan Tamalanrea, Kabupaten Makassar yang berjumlah 74 siswa dengan alasan siswa pada kelas tersebut sudah dapat memahami pesan dan pertanyaan yang diberikan peneliti. Sampel pada penelitian ini adalah seluruh siswa kelas III, IV, dan V sebanyak 74 siswa yang diikutsertakan dalam penelitian (total sampling).

\section{Hasil}

Kegiatan yang kami lakukan yang dimulai dari tahap persiapan hingga evaluasi selama kurang lebih 4 bulan memberi dampak yang positif terhadap perilaku dan pengetahuan anak SD Inpres Kera-Kera kelas 3,4 dan 5. pretest-posttest yang diberikan berisi 10 pertanyaan dengan 2 jenis yaitu pertanyaan mengenai perilaku makan sehari-hari dan pengetahuan mengenai makanan bergizi

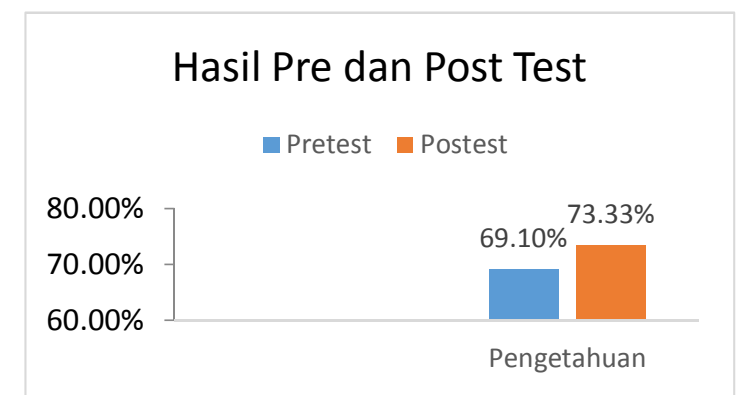

Gambar 1. Perbandingan Hasil pretest-posttest mengenai pengetahuan

Dari diagram diatas dapat dilihat bahwa pengetahuan anak SD Inpres Kera-Kera kelas 3,4 dan 5 memiliki peningkatan setelah dilakukan penyuluhan dan permainan game Qogisaki (Quarted Gizi Seimbang Masa Kini) yaitu dari $69.10 \%$ menjadi $73.33 \%$. 


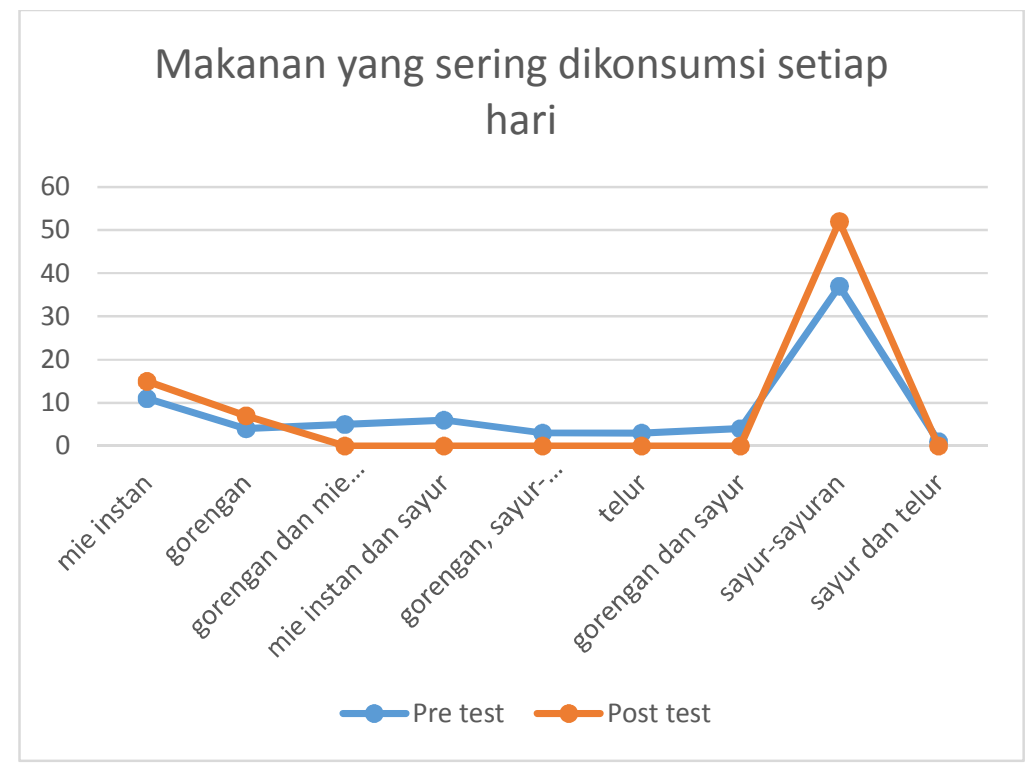

Gambar 2. Perbandingan Hasil Pre-post test Pertanyaan yang Sering Dikonsumsi Setiap Hari

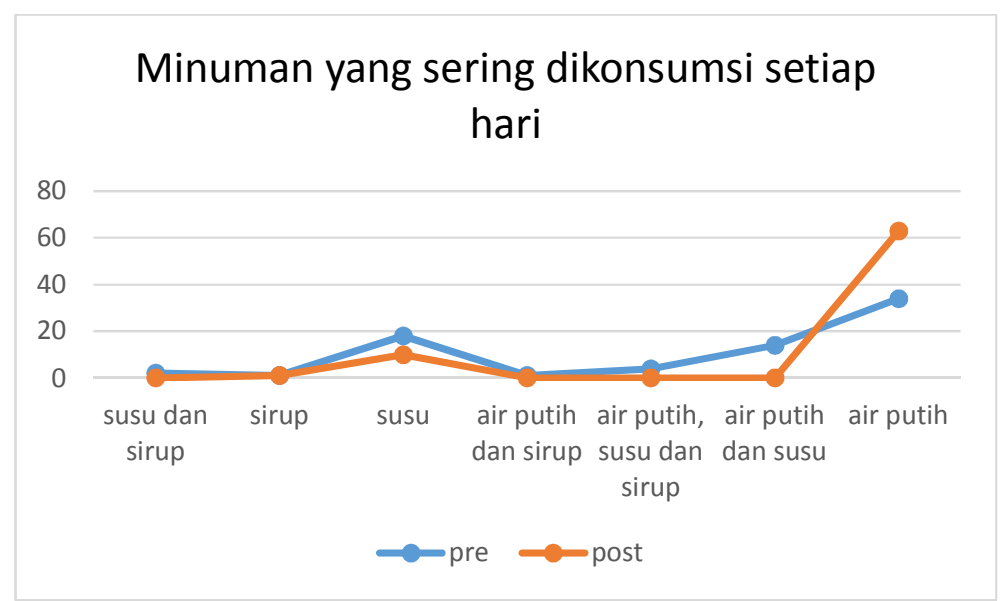

Gambar 3. Perbandingan Hasil Pre-post test Pertanyaan Minuman yang Sering Dikonsumsi Setiap Hari 


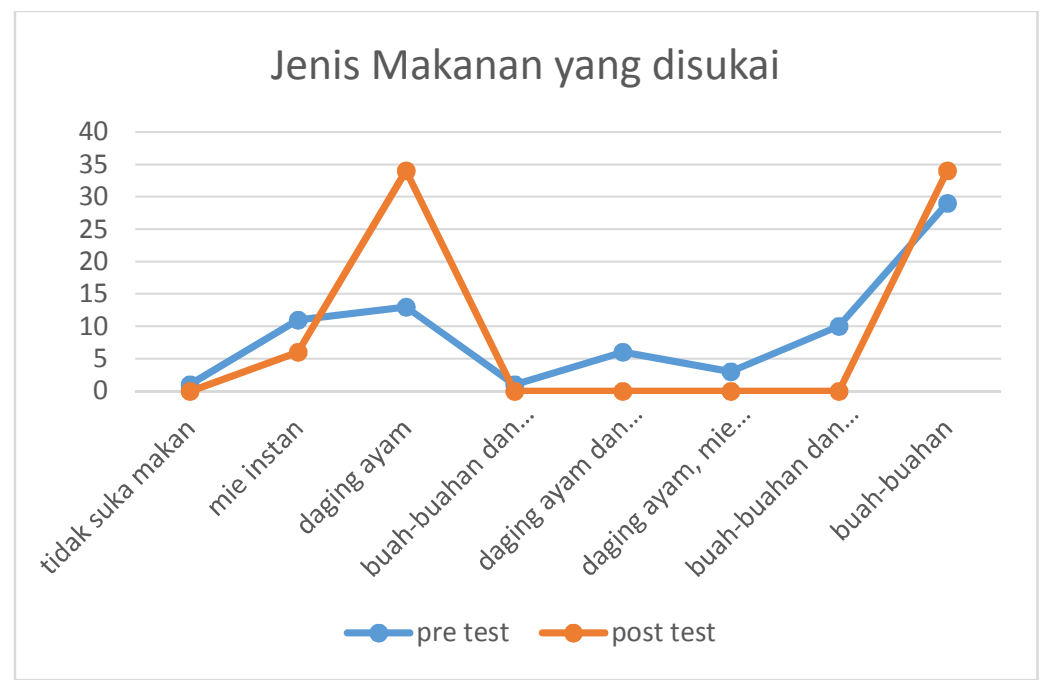

Gambar 4. Perbandingan Hasil Pre-post test Pertanyaan Jenis Makanan yang Disukai

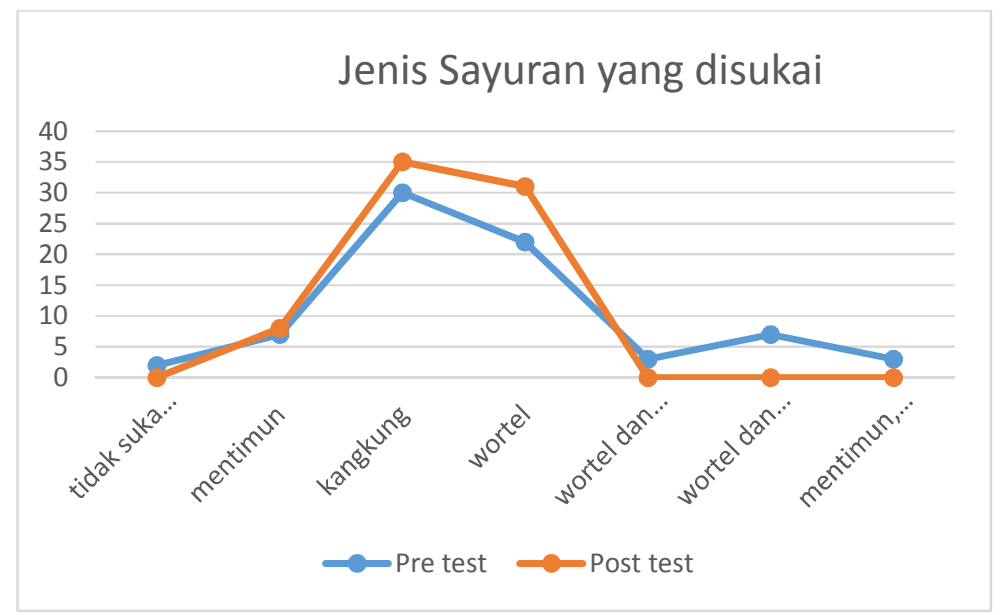

Gambar 5. Perbandingan Hasil Pre-post test Pertanyaan Jenis Sayuran yang Disukai

Terdapat 4 pertanyaan mengenai perilaku sehari-sehari anak SD Inpres Kera-Kera dan semua pertanyaan mengenai perilaku tersebut mengalami perubahan sebelum dan setelah pemberian informasi melalui permainan quarted. Perilaku sering makan sayuran tiap hari mengalami peningkatan dari 37 anak menjadi 52 anak. Perilaku konsumsi air putih meningkat drastis dari 34 menjadi 63 anak, dan penurunan konsumsi minuman manis dari 39 menjadi 10 anak. Selain itu, jenis makanan yang disukai juga berubah dari menyukai makanan yang kurang sehat menjadi lebih menyukai makanan sehat (menyukai mie instan menurun dari 11 ke 6 anak, menyukai buah-buahan meningkat dari 29 menjadi 34 anak, jumlah anak yang tidak sukan makan sayur juga menurun). 


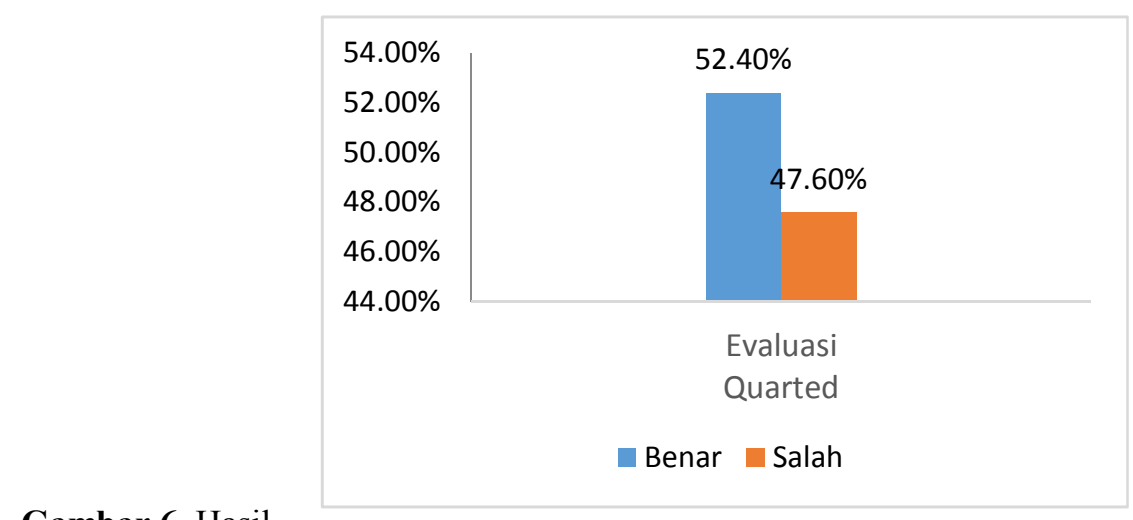

Gambar 6. Hasil

Evaluasi isi Quarted

Dari diagram diatas yang berisi Evaluasi isi quarted yang diberikan dalam bentuk pertanyaan sebanyak 5 nomor yang berkaitan dengan isi quarted yang telah di mainkan dapat dilihat bahwa sebanyak 52,4\% anak SD mampu menjawab semua pertanyaan dengan benar.

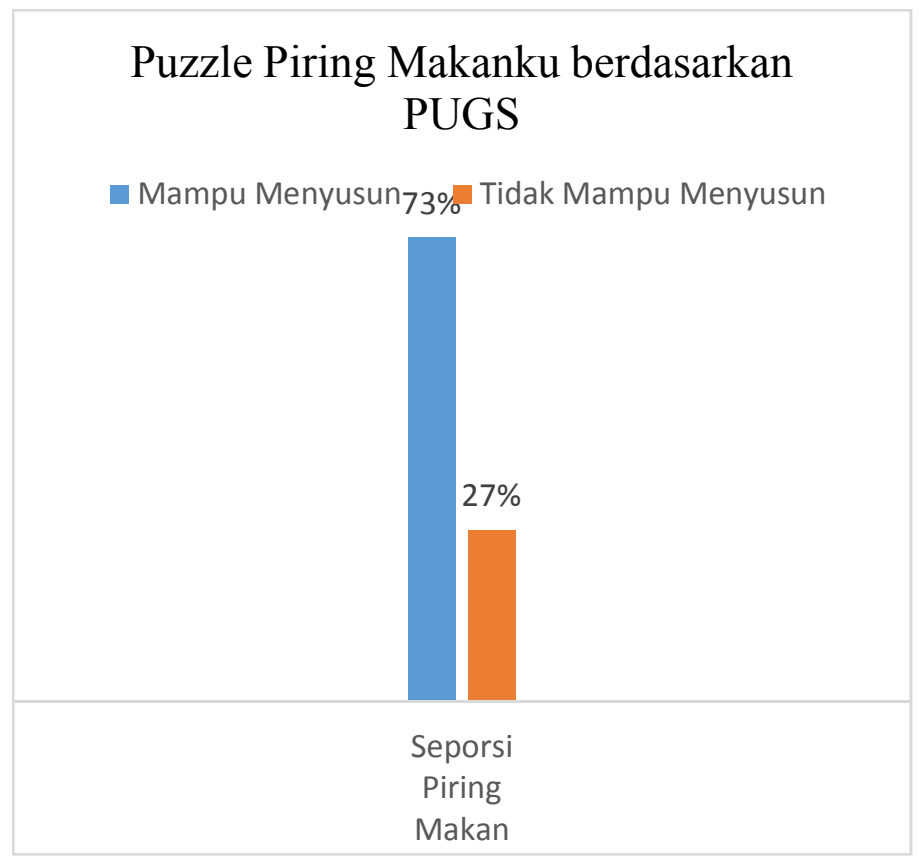

Gambar 7. Hasil Kemampuan Menyusun Puzzle Piring Makanku

Selain evaluasi isi quarted dengan memberikan pertanyaan untuk menilai keberhasilan kegiatan ini juga dilakukan penyusunan puzzle piring makanku untuk melihat kemampuan dan pengetahuan anak SD mengenai kebutuhan gizi seimbang dan sebanyak $73 \%$ mampu menyusun seporsi ilustrasi piring makanku sesuai dengan PUGS.

\section{PEMBAHASAN}

\section{A. Pengaruh Edukasi Gizi Seimbang dengan Metode Permainan QOGISAKI (Quarted Gizi Seimbang Masa Kini) Terhadap Tingkat Pengetahuan Gizi Seimbang}


Edukasi Gizi merupakan upaya yang dilakukan untuk mengajak seseorang berperilaku sehat dengan cara ajakan, himbauan ataupun persuasi dengan tujuan meningkatkan kesehatan Masyarakat dengan menjunjung prinsip gizi seimbang. Edukasi gizi dengan metode Permainan Quarted merupakan pemahaman pengetahuan tentang gizi seimbang kepada responden dengan metode bermain Quarted. Tingkat pengetahuan responden pada saat pre-test menunjukkan sebagian besar responden memiliki tingkat pengetahuan cukup. Sebanyak 69,10\% responden menjawab benar Setelah diberikan Edukasi Gizi dengan metode Permainan Quarted terjadi peningkatan pengetahuan dari 69,10\% mejadi 73,33\%. Hal ini menunjukkan bahwa Permainan Quarted mempunyai pengaruh terhadap tingkat pengetahuan responden.

Hasil nilai pre-test dan post-test dianalisis menggunakan uji statistik Wilcoxon. Hasil uji statistik menunjukkan adanya peningkatan tingkat pengetahuan pada responden pada saat pre-test (sebelum mendapatkan edukasi gizi dengan metode Permainan Quarted) dengan pada saat post-test (setelah mendapatkan edukasi gizi dengan metode Permainan Quarted). Hal ini dapat terlihat dengan adanya perbedaan yang bermakna dari hasil rata-rata pre-test dan post-test pada responden

Beberapa faktor yang mempengaruhi pengetahuan adalah tingkat pendidikan, informasi, budaya, pengalaman dan sosial ekonomi.Pengetahuan awal responden kelompok eksperimen yang cukup dan baik dimungkinkan karena adanya faktor penunjang yang mempengaruhi pengetahuan, misalnya pengalaman dari luar dan informasi seperti informasi dari Sekolah, media massa maupun media elektronik.

Salah satu cara menyampaikan informasi kesehatan adalah dengan edukasi gizi. Pendidikan adalah upaya agar masyarakat berperilaku mengadopsi perilaku kesehatan dengan cara ajakan, memberikan informasi melalui kegiatan yang disebut pendidikan atau promosi kesehatan. Salah satu cara menyampaikan informasi kesehatan adalah dengan metode Permainan Quarted. Penyampaian informasi dengan Permainan Quarted cocok diterapkan pada anak usia sekolah dasar.

Permainan dilakukan dengan membagi responden menjadi kelompok-kelompok kecil yang terdiri dari 4 responden dalam 1 kelompok. Permainan dilakukan pada waktu bersamaan dengan didampingi oleh 1 fasilitator pada setiap kelompok. Permainan dan peraturan Quarted dilakukan seperti pada umumnya, namun terdapat aturan tambahan, yaitu setiap pemain harus membaca pesan atau informasi yang tercantum pada kolom quarted tersebut saat pemain menyebutkan salah satu klue yang terdapat pada quartednya. Permainan dilakukan hingga mendapatkan sang juara atau yang paling banyak mengumpulkan klue yang sama pada quarted tersebut. Adapun untuk setiap responden diperoleh dari hasil kluster dari peneliti yaitu kelas III, IV, dan V. Pemain yang memenangkan permainan akan mendapatkan hadiah dari peneliti. Setelah responden selesai bermain pukul 11.30 WITA kemudian responden diberikan konsumsi oleh panitia yang di dalanya berisi menu makanan yang memenuhi gizi seimbang. Kemudian agenda berikutnya yaitu penutupan. Adapun untuk melihat perubahan perilaku dan pengetahuan terhadap kebiasaan makan dengan memainkan QOGISAKI maka peneliti memberikan jeda waktu selama 1 bulan 4 hari setelah itu dilakukan tahapan berikutnya yaitu tahapan evaluasi dengan memberikan post test kepada responden yang diisi selama 20 menit. Setelah dilakukan post test responden diberikan satu piring tiap responden untuk menyusun menu makan siang dengan cara responden diberikan gambar-gambar makanan baik itu makanan yang sehat dan memenuhi gizi seimbang dan makanan yang kurang sehat yang tidak bergizi lalu responden menempelkan ke dalam piringnya. diharapkan dengan dilakukannya edukasi gizi tentang gizi seimbang dengan metode Permainan Quarted dapat tercapai output peningkatan pengetahuan tentang perilaku dan merubah sikap kearah yang positif.

Edukasi gizi yang diberikan kepada responden dengan Permainan Quarted dilakukan dengan memberikan pesan atau informasi tentang gizi seimbang melalui gambar-gambar yang terdapat pada setiap kolom Quarted. Sebelum diberikan edukasi gizi dengan metode Permainan Quarted, terlebih dahulu dilakukan pre-test pada pukul 08.00 WITA sampai dengan 10.00 WITA. Kemudian dilakukan 
edukasi gizi dengan metode QOGISAKI. Permainan dilakukan setelah responden selesai melakukan pre-test yaitu pukul 08.30 WITA sampai selesai.

Dari hasil penelitian ini dapat dibuktikan bahwa edukasi gizi tentang gizi seimbang dengan metode QOGISAKI cukup efektif dalam memberikan pengaruh dalam meningkatkan pengetahuan siswa Sekolah Dasar Inpres Kera-kera. Edukasi gizi dengan metode QOGISAKI tentang gizi seimbang diberikan kepada responden dengan karakter usia sekolah dasar. Perubahan tingkat pengetahuan pada responden dimungkinkan karena responden telah belajar dengan media QOGISAKI dengan membaca pesan gizi seimbang yang terdapat pada quarted dan telah menambah wawasan responden.

\section{B. Pengaruh Edukasi Gizi dengan Metode QOGISAKI (Quarted Gizi Seimbang Masa Kini) terhadap Perilaku Makan}

Terdapat 4 pertanyaan mengenai perilaku sehari-sehari anak SD Inpres Kera-Kera dan semua pertanyaan mengenai perilaku tersebut mengalami perubahan sebelum dan setelah pemberian informasi melalui permainan quarted. Perilaku sering makan sayuran tiap hari mengalami peningkatan dari 37 anak menjadi 52 anak. Perilaku konsumsi air putih meningkat drastis dari 34 menjadi 63 anak, dan penurunan konsumsi minuman manis dari 39 menjadi 10 anak. Selain itu, jenis makanan yang disukai juga berubah dari menyukai makanan yang kurang sehat menjadi lebih menyukai makanan sehat (menyukai mie instan menurun dari 11 ke 6 anak, menyukai buah-buahan meningkat dari 29 menjadi 34 anak, jumlah anak yang tidak sukan makan sayur juga menurun).

Berdasarkan teori perkembangan kognitif dari piaget anak usia 6-12 tahun ini perkembangan kognitifnya berada pada tahap konkret operasional. Artinya anak mencapai struktur logika tertentu yang memungkinkan mereka membentuk beberapa operasi mental, namun masih terbatas pada obyek obyek yang konkret. (Nuryanti, 2008). Kemampuan mereka bertambah dalam hal mendeskripsikan pengalaman dan mengutarakan apa yang mereka pikirkan dan mereka rasakan. Anak mengalami perubahan kemampuan berpikir, dari yang sebelumnya lebih berpusat pada diri sendiri menjadi mampu berpikir juga tentang hal lain di luar dirinya. Anak juga mulai mampu memahami hubungan sebab akibat.

Perilaku merupakan variabel yang membutuhkan waktu lebih panjang untuk mengalami perubahan. Hal ini sesuai dengan teori Kurt Lewin yang mengatakan bahwa perilaku manusia adalah suatu keadaan yang seimbang antara kekuatan pendorong dan kekuatan penahan, dan perilaku ini dapat berubah jika terjadi ketidakseimbangan antara kedua kekuatan tersebut, sehingga untuk mengebuah perilaku seseorang tersebut membutuhkan waktu yang lebih lama. namun, meskipun demikian, walaupun hanya sebulan waktu pengukuran dilakukan, perubahan sudah dapat dilihat pada perilaku anak dalam hal konsumsi makanan sehat setelah terpapar informai mengenai gizi seimbang melalui penyuluhan dan permainan gam quarted sendiri.

Menurut Notoatmodjo (2003), penyuluhan kesehatan tidak dapat lepas dari media, pesan-pesan di sampaikan dengan mudah dipahami, dan lebih menarik. Media juga dapat menghindari kesalahan persepsi, memperjelas informasi, mempermudah pengertian, dapat mengurangi komunikasi yang verbalistik, dan memperlancar komunikasi. Dengan demikian, sasaran dapat mempelajari pesan tersebut dan mampu memutuskan mengadopsi perilaku sesuai dengan pesan-pesan yang disampaikan.

\section{PENUTUP}

\section{A. SIMPULAN}

1. Tingkat pengetahuan responden pada saat pre-test yaitu dari 69.10 poin meningkat menjadi 73.33 poin pada saat postest.

2. Perilaku sering makan sayuran tiap hari mengalami peningkatan dari 37 anak menjadi 52 anak. Perilaku konsumsi air putih meningkat drastis dari 34 menjadi 63 anak, dan penurunan konsumsi 
minuman manis dari 39 menjadi 10 anak. Selain itu, jenis makanan yang disukai juga berubah dari menyukai makanan yang kurang sehat menjadi lebih menyukai makanan sehat (menyukai mie instan menurun dari 11 ke 6 anak, menyukai buah-buahan meningkat dari 29 menjadi 34 anak, jumlah anak yang tidak sukan makan sayur juga menurun).

3. Evaluasi isi quarted yang diberikan dalam bentuk pertanyaan sebanyak 5 nomor yang berkaitan dengan isi quarted yang telah di mainkan dapat dilihat bahwa sebanyak 52,4\% anak SD mampu menjawab semua pertanyaan dengan benar.

4. Kemampuan dan pengetahuan anak SD mengenai kebutuhan gizi seimbang dan sebanyak $73 \%$ mampu menyusun seporsi ilustrasi piring makanku sesuai dengan PUGS.

\section{Daftar Pustaka}

1. Widyatmoko, Marsetyo Dwi, Tri Puji Kurniawan \& Anisa Catur Wijayanti. 2014. Pengaruh Pendidikan Kesehatan Dengan Metode Permainan Tradisional Engklek Terhadap Pengetahuan Dan Sikap Merokok Siswa Di Sekolah Dasar Negeri Kuniran 3 Kecamatan Sine Kabupaten Ngawi. Surakarta: Fakultas Ilmu Kesehatan Universitas Muhammadiya Surakarta.

2. Djaiman, Sri Poedji Hastoety \& Noviati Fuada. 2015. Faktor-Faktor Pembeda Provinsi Yang Mengalami Beban Gizi Ganda (BGG) Pada Anak Balita Di Indonesia. Penelitian Gizi dan Makanan, Vol. 38 (1): 11-20.

3. Yudianto, Andi, Indah Mukarromah \& Athi' Linda Yani. 2012. Pengaruh Stimulasi Permainan Ular Tangga Terhadap Perubahan Sikap Siswa Tentang Demam Berdarah Dengue. Jombang: Fakultas Ilmu Kesehatan UNIPDU 